\title{
KUALITAS CITRA CT ABDOMEN NON KONTRAS BERDASARKAN VARIASI ROTATION TIME (Studi Penelitian dengan Menggunakan Phantom)
}

\section{IMAGE QUALITY OF CT ABDOMEN NON CONTRAST BASED ON VARIATIONS OF ROTATION TIME (Research Study Using Phantom)}

\author{
Dyah Arum Larasati ${ }^{1}$, Gatot Murti Wibowo ${ }^{2}$, Sri Mulyati ${ }^{3}$ \\ ${ }^{1,2,3)}$ Health Polytechnics of Semarang-Indonesia \\ e-mail: dyaharumlarasati260912@gmail.com
}

\begin{abstract}
Backgroud: Has conducted research in Radiology Department of RS Telogorejo Semarang regarding image quality of CT Abdomen non contrast based on variations of rotation time in phantom, especially noise and spatial resolution. This study was conducted to determine the difference in rotation time variation of the image quality (noise and spatial resolution) on a non-contrast CT abdomen and know the value rotation time is used in order to produce optimal image quality with the variations of the rotation time of $0.5 \mathrm{~s}, 0,6 \mathrm{~s}, 0.7 \mathrm{~s}, 0.8 \mathrm{~s}, 0.9 \mathrm{~s}$ and 1.0 s.

Methods: This research is a quantitative study with an experimental approach. Data have been collected from December 2016 to January 2017 in Radiology Department of RS Telogorejo Semarang. CT abdomen non-contrast examinations performed by using the modality of 64 slice CT scan and the data collected by assessing noise and spatial resolution in phantom. Further, data were tested with data normality test then the statistical test by Kruskal Wallis test has been used to determine the difference in image quality was noise and spatial resolution on non-contrast abdominal CT followed by Post Hoc test Mann Whitney on spatial resolution to determine a significant difference between the variation of rotation time .

Results: The results of this study showed significant differences in spatial resolution with $\mathrm{p}$ value $<0.001$ and there were no significant difference in the value of noise with $\mathrm{p}$ value $>0.001$ non-contrast abdominal CT.

Conclusion: Values optimal rotation time for CT Abdomen non contrast with variation of the rotation time are $0.5 \mathrm{~s}, 0.6 \mathrm{~s}, 0.7 \mathrm{~s}, 0.8 \mathrm{~s}, 0.9 \mathrm{~s}$ and $1.0 \mathrm{~s}$ for the spatial resolution is $0.6 \mathrm{~s}$ and $1.0 \mathrm{~s}$ for the noise.
\end{abstract}

Keywords : Image quality, noise, spatial resolution, rotation time, CT abdomen non contrast

\section{PENDAHULUAN}

Abdomen merupakan suatu rongga terbesar dalam tubuh, bentuk lonjong dan meluas dari atas diafragma sampai pelvis bawah. Terdiri dari beberapa organ yaitu hepar, ginjal, limpa, pankreas, lambung, usus yang berada diatas rongga pelvis. Evaluasi CT Abdomen membutuhkan perhatian paling banyak untuk persiapan pasien daripada evaluasi CT area tubuh yang lain (Romans, Loise. E, 2011).

Banyak faktor yang mempengaruhi kualitas citra yang dihasilkan, seperti noise dan spasial resolusi. Beberapa faktor yang dapat dikontrol oleh operator adalah milliampere $(\mathrm{mA})$ level, scan time, slice thickness, field of view, rekontruksi algoritma, dam kilovolt-peak (kVp). Ketika menggunakan metode helical, operator juga dapat memilih pitch. Sebagai grup, faktor tersebut biasa disebut sebagai parameter scanning (Romans, Loise. E, 2011).

Menurut American College of Radiology (2016) walaupun banyak pengaturan CT Scan yang otomatis, sejumlah parameter teknis tetap tergantung pada operator. Menurut Beeres M, dkk (2014) gantry rotation time pada Computed tomography (CT) adalah salah satu faktor yang mempengaruhi kualitas citra Hingga saat ini belum banyak laporan penelitian tentang pengaruh rotation time pada kualitas citra CT Scan.

Penelitian yang dilakukan Beeres M, dkk (2014) menghasilkan rotation time yang cepat menghasilkan banyak artefak, noise, dan berkurangnya kualitas citra walaupun tidak ada perbedaan yang signifikan pada paparan radiasi antara rotation time cepat dan lambat.

Pemeriksaan CT abdomen non kontras sudah menjadi pemeriksaan rutin untuk banyak kasus patologis. Namun informasi tentang kualitas citra khususnya tentang rotation time pada pemeriksaan CT abdomen non kontras masih belum banyak diketahui.

Kualitas citra CT Scan yang optimal akan mempermudah dokter radiologi dalam melakukan ekspertisi citra CT Scan. Sehingga, untuk menghasilkan kualitas citra yang optimal seorang radiografer diharapkan mampu menentukan faktorfaktor seperti noise, spasial resolusi, dan sebagainya yang dapat mempengaruhi kualitas citra.

\section{METODE}

Penelitian dilakukan di Instalasi Radiologi Rumah Sakit Telogorejo Semarang tentang kualitas citra CT abdomen non kontras berdasarkan variasi rotation time pada phantom. Perubahan nilai rotation time akan mempengaruhi kualitas citra khususnya noise dan spasial resolusi. Penelitian ini dilakukan untuk mengetahui adanya perbedaan variasi rotation time terhadap kualitas citra (noise dan spasial resolusi) pada CT abdomen non kontras dan mengetahui nilai rotation 
time yang digunakan sehingga dapat menghasilkan kualitas citra yang optimal dengan variasi nilai rotation time $0,5 \mathrm{~s}, 0,6$ $\mathrm{s}, 0,7 \mathrm{~s}, 0,8 \mathrm{~s}, 0,9 \mathrm{~s}$, dan $1,0 \mathrm{~s} . J e n i s$ penelitian dalam karya tulis ilmiah ini adalah penelitian eksperimental. Pemeriksaan CT abdomen non kontras dilakukan dengan menggunakan modalitas CT-Scan 64 slice dan cara pengumpulan data dengan melakukan penilaian pada phantom terhadap noise dan spasial resolusi. Dilakukan uji normalitas data selanjutnya digunakan uji statistik Kruskal wallis untuk melihat perbedaan kualitas citra yaitu noise dan spasial resolusi pada CT abdomen non kontras dilanjutkan dengan uji Post Hoc Mann Whitney pada variasi spasial resolusi untuk melihat perbedaan yang bermakna antara variasi rotation time 0,6 s dengan variasi yang lain.

\section{HASIL}

\section{Hasil Penelitian Variasi Rotation Time terhadap Kualitas} Citra (Noise)

Pengukuran nilai noise setelah dilakukan scanning kemudian dilakukan pengukuran Region of Interest (ROI) pada 19 citra yang dihasilkan di pusat phantom.

\begin{tabular}{cc}
\multicolumn{2}{c}{ Tabel 1. Hasil Pengukuran Noise } \\
\hline Rotation Time & Hasil Pengukuran Noise \\
\hline $0,6 \mathrm{~s}$ & 3,57 \\
$0,5 \mathrm{~s}$ & 3,59 \\
$0,7 \mathrm{~s}$ & 3,54 \\
$0,8 \mathrm{~s}$ & 3,43 \\
$0,9 \mathrm{~s}$ & 3,35 \\
$1,0 \mathrm{~s}$ & 3,32 \\
\hline
\end{tabular}

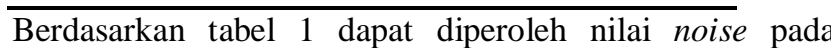
rotation time citra $\mathrm{CT}$ abdomen non kontras yaitu rotation time rutin yang digunakan di RS Telogorejo yaitu 0,6 s menghasilkan nilai noise senilai 3,57, dan variasi rotation time lain yang digunakan yaitu $0,5 \mathrm{~s}$ senilai $3,59,0,7 \mathrm{~s}$ senilai 3,54 , $0,8 \mathrm{~s}$ senilai $3,43,0,9 \mathrm{~s}$ senilai 3,35 dan $1,0 \mathrm{~s}$ senilai 3,32 . Nilai noise terendah 3,32 pada variasi rotation time $1,0 \mathrm{~s}$ dan nilai noise tertinggi 3,59 pada variasi rotation time $0,5 \mathrm{~s}$. Nilai rotation time pada $0,6 \mathrm{~s}$ dengan variasi $0,5 \mathrm{~s}$ relatif sama.

Hasil Penelitian Variasi Rotation Time terhadap Kualitas Citra (Spasial Resolusi)

Tabel 1. variasi

\begin{tabular}{cccccccccccc}
\hline \multirow{2}{*}{ Perlakuan } & \multicolumn{1}{c}{ Nilai Infomasi Anatomi } & & Total \\
\cline { 2 - 11 } & 1 & 2 & 3 & 4 & 5 & 6 & 7 & 8 & 9 & 10 & \\
\hline Fat Sat & 6 & 7 & 7 & 7 & 8 & 6 & 7 & 6 & 7 & 6 & 67 \\
Non Fat & 9 & 9 & 9 & 9 & 9 & 9 & 9 & 8 & 9 & 8 & 88 \\
Sat & & & & & & & & &
\end{tabular}

Pengukuran spasial resolusi menggunakan citra yang sudah sesuai pengujian spasial resolusi, peneliti menggunakan 13 citra, kemudian mengatur window width $100 \mathrm{HU}$ dan window level $110 \mathrm{HU}$. Setelah itu menghitung high contrast targets yang terlihat jelas kemudian dijumlahkan pada setiap citra dan mencatat hasilnya kedalam tabel 2.

Berdasarkan tabel 2 diperoleh nilai spasial resolusi pada rotation time citra $\mathrm{CT}$ abdomen non kontras yaitu nilai rotation time 0,6 s yang rutin digunakan di RS Telogorejo adalah 15 , sedangkan nilai rotation time $0,5 \mathrm{~s}$ senilai $13,0,7 \mathrm{~s}$ senilai $13,0,8 \mathrm{~s}$ senilai $11,0,9 \mathrm{~s}$ senilai 12 dan $1,0 \mathrm{~s}$ senilai 14 . Nilai tertinggi terdapat pada rotation time $0,6 \mathrm{~s}$ dan nilai terendah pada $0,8 \mathrm{~s}$.

Tabel 2. Hasil Penghitungan Spasial Resolusi

\begin{tabular}{cc}
\hline Rotation Time & $\begin{array}{c}\text { Hasil Penghitungan } \\
\text { Spasial Resolusi }\end{array}$ \\
\hline $0,6 \mathrm{~s}$ & 15 \\
$0,5 \mathrm{~s}$ & 13 \\
$0,7 \mathrm{~s}$ & 13 \\
$0,8 \mathrm{~s}$ & 11 \\
$0,9 \mathrm{~s}$ & 12 \\
$1,0 \mathrm{~s}$ & 14 \\
\hline
\end{tabular}

\section{Hasil Uji Statistik Variasi Rotation Time Terhadap Kualitas Citra}

Hasil penghitungan kualitas citra pada citra sesuai kelompok pengujian yaitu noise dan spasial resolusi terhadap 6 variasi rotation time dianalisis dengan menggunakan uji Kruskal Wallis kemudian di uji Mann Whitney untuk melihat perbedaan antar kelompok variasi rotation time yang terlebih dahulu dilakukan uji normalitas data menggunakan uji Shapiro Wilk pada spasial resolusi dan uji Kolmogorov Smirnov pada noise. Pada uji normalitas data nilai $\mathrm{p}<0,05$ maka data distribusi tidak normal kemudian uji statistik dilanjutkan dengan uji Kruskal Wallis untuk noise dan spasial resolusi, dan uji Mann Whitney pada spasial resolusi untuk megetahui perbedaan antar variasi.

Dari uji statisik Kruskal Wallis pada 6 variasi rotatoion time terhadap kualitas citra nilai $\rho$ value $<0,05$ yang artinya tidak ada perbedaan variasi rotation time terhadap kualitas citra yaitu spasial resolusi, dan setelah mendapat hasil uji ada beda pada uji statistik Kruskal Wallis untuk mengetahui perbedaan antar kelompok pada spasial resolusi maka peneliti melanjutkan uji statistik dengan menggunakan uji Pos Hoc Mann-Whitney antara variasi rotation time satu dengan yang lainnya.Untuk menentukan perbedaan antar kelompok maka uji statsitik dilanjutkan dengan menggunakan uji Pos Hoc Mann Whitney dengan hasil, sebagai berikut :

Tabel 3 Hasil Uji Pos Hoc Mann Whitney

\begin{tabular}{cc}
\hline Variasi Rotation Time & Signifikansi \\
\hline $0,6 \mathrm{~s}$ &, 0000 \\
$0,5 \mathrm{~s}$ &, 0000 \\
$0,7 \mathrm{~s}$ &, 0000 \\
$0,8 \mathrm{~s}$ &, 0000 \\
$0,9 \mathrm{~s}$ &, 0000 \\
$1,0 \mathrm{~s}$ &, 0000 \\
\hline
\end{tabular}

\section{DISKUSI}

Penelitian yang telah dilakukan pada phantom pada protokol CT Abdomen non kontras tentang kualitas citra berdasarkan variasi rotation time menghasilkan 49 citra dengan 19 citra untuk pengukuran nilai noise, 13 citra untuk pengukuran nilai spasial resolusi dan 17 citra tidak digunakan 
yang kemudian dinilai menggunakan Region of Interest (ROI) untuk menilai noise. Kemudian hasil penilaian citra tersebut diolah secara komputerisasi menggunakan software SPSS selanjutnya dianalisa.

Penilaian citra phantom untuk penghitungan nilai noise dilakukan dengan menggunakan software radiant dicom dengan cara meletakkan region of interest (ROI) pada pusat citra setiap variasi rotation time $0,5 \mathrm{~s} ; 0,6 \mathrm{~s} ; 0,7 \mathrm{~s} ; 0,8 \mathrm{~s} ; 0,9 \mathrm{~s}$; dan 1,0 s kemudian mencatat hasil mean yang dihasilkan. Setelah menghitung noise maka selanjutnya melakukan penghitungan spasial resolusi dengan menghitung high contrast targets. Semakin banyak high contrast targets yang terhitung maka semakin baik citra tersebut (Romans, Lois, E. 2011).

Selanjutnya setelah semua data pengujian kualitas citra diperoleh dilakukan uji normalitas data nilai kualitas citra dengan uji Shapiro-Wilk, sebaran data yang dihasilkan pada kualitas citra yaitu noise dan spasial resolusi tidak normal sehingga dianalisa dengan uji statistik Kruskal Wallis, pada spasial resolusi dihasilkan tingkat kepercayaan (confident level) $95 \%(\alpha=5 \%)$, menunjukkan bahwa nilai kemaknaan (p-value) kurang dari $\alpha(\mathrm{p}<0,05)$ maka dapat disimpulkan terdapat perbedaan kualitas citra (spasial resolusi) terhadap rotation time pada $\mathrm{CT}$ abdomen non kontras. Analisis data dilanjutkan dengan menggunakan uji Pos Hoc Mann Whitney untuk menguji perbedaan antara variasi $0,6 \mathrm{~s}$ dengan kelompok variasi yang lain. Kemudian hasil uji analisis nilai noise menghasilkan nilai kemaknaan (p-value) lebih dari $\alpha$ ( $\mathrm{p}>0,05$ ) maka dapat disimpulkan terdapat tidak ada perbedaan yang signifikan pada kualitas citra (noise) terhadap rotation time pada CT abdomen non kontras. Selanjutnya, untuk mengetahui nilai rotation time yang terbaik dilihat dari nilai rata-rata noise dan spasial resolusi yang dihasilkan dengan dianalisa secara deskriptif

\section{Perbedaan rotation time terhadap kualitas citra CT abdomen non kontras}

Berdasarkan hasil SPSS uji Kruskal Wallis pada noise menyatakan Ho diterima atau Ha ditolak bahwa tidak ada perbedaan yang signifikan pada noise terhadap variasi rotation time dengan nilai kemaknaan 0,419 $(\mathrm{p}>0,05)$ pada kualitas citra terhadap variasi rotation time $\mathrm{CT}$ abdomen non kontras. Jadi, variasi rotation time terhadap kualitas citra (noise) tidak menghasilkan perbedaan yang signifikan.

Berdasarkan hasil SPSS uji Kruskal Wallis pada spasial resolusi menyatakan Ho ditolak atau Ha diterima bahwa ada perbedaan pada spasial resolusi terhadap variasi rotation time dengan nilai kemaknaan $0,000(\mathrm{p}<0,05)$ pada kualitas citra terhadap variasi rotation time $\mathrm{CT}$ abdomen non kontras. Sehingga untuk menentukan perbedaan variasi rotatin time 0,6 s dengan variasi lainnya maka setelah mendapatkan hasil uji statistik Kruskal Wallis pada spasial resolusi dilanjutkan uji pos hoc Mann Whitney untuk melihat perbedaan antar kelompok 0,6 s dengan variasi lainnya secara statistik ada perbedaan yang signifikan karena hasil menunjukkan $\mathrm{p}<0.05$. Jadi, variasi rotation time terhadap kualitas citra (spasial resolusi) menghasilkan perbedaan yang signifikan.

\section{Nilai rotation time yang dapat menghasilkan kualitas citra yang optimal}

Berdasarkan tabel 1 diketahui untuk noise setiap variasi rotation time menunjukan adanya penurunan noise pada kenaikan nilai rotation time, yaitu $0,5 \mathrm{~s}$ dengan nilai noise rata-rata $3,59,0,6 \mathrm{~s}$ dengan nilai noise rata-rata $3,57,0,7 \mathrm{~s}$ dengan nilai noise rata-rata $3,54,0,8 \mathrm{~s}$ dengan nilai noise ratarata 3,43, 0,9 s dengan nilai noise rata-rata 3,35 dan 1,0 s dengan nilai noise rata-rata 3,32, dengan hasil tersebut dapat dilihat nilai 1,0 s menghasilkan noise rata-rata paling terendah dan nilai 0,5 s menghasilkan noise rata-rata tertinggi.

Menurut Beeres, M, dkk (2014) pengukuran secara obyektif menggunakan signal to noise ratio (SNR) menghasilkan rotation time yang cepat menghasilkan banyak artefak, noise, dan berkurangnya kualitas citra walaupun tidak ada perbedaan yang signifikan pada paparan radiasi antara rotation time cepat dan lambat.

Berdasarkan tabel 2 diketahui untuk spasial resolusi setiap variasi rotation time terjadi peningkatan dan penurunan secara signifikan. Rotation time $0,6 \mathrm{~s}$ menghasilkan spasial resolusi sejumlah 15 , nilai rotation time $0,5 \mathrm{~s}$ dan $0,7 \mathrm{~s}$ menghasilkan spasial resolusi sejumlah 13 , nilai rotation time $0,9 \mathrm{~s}$ menghasilkan spasial resolusi sejumlah 12 , dan nilai rotation time 1,0 s menghasilkan spasial resolusi sejumlah 14 .

Jadi, kualitas citra yang optimal dihasilkan pada nilai rotation time $1,0 \mathrm{~s}$ dengan nilai noise yang rendah dan rotation time $0,6 \mathrm{~s}$ dengan menghasilkan nilai spasial resolusi yang tinggi.

\section{SIMPULAN}

Terdapat perbedaan variasi rotation time terhadap kualitas citra yaitu spasial resolusi CT abdomen non kontras dengan hasil uji statistik menggunakan uji Kruskal Wallis menyatakan Ho ditolak yang artinya ada perbedaan pada nilai spasial resolusi dan dilanjutkan dengan pos hoc Mann Whitney dengan hasil ada beda antar kelompok dan hasil uji statistik menggunakan uji Kruskal Wallis untuk kualitas citra yaitu noise menyatakan Ho diterima yang artinya tidak ada perbedaan pada nilai noise.

Hasil statistik deskriptif menghasilkan variasi rotation time $0,5 \mathrm{~s}, 0,6 \mathrm{~s}, 0,7 \mathrm{~s}, 0,8 \mathrm{~s}, 0,9 \mathrm{~s}$, dan $1,0 \mathrm{~s}$ terhadap kualitas citra pada CT abdomen non kontras yaitu noise dan spasial resolusi menghasilkan penurunan nilai pada noise dan spasial resolusi yang optimal pada rotation time yaitu $0,6 \mathrm{~s}$. Nilai dari rotation time $\mathrm{CT}$ abdomen non kontras menghasilkan kualitas citra yaitu noise yang optimal pada 1,0 s dan spasial resolusi yang optimal pada $0,6 \mathrm{~s}$.

\section{DAFTAR PUSTAKA}

American College of Radiology (ACR). 2016. ACR-SPR Practice Parameter for the Performance of Computed Tomography (CT) of the Abdomen and Computed Tomography (CT) of the Pelvis. http://www.acr.org/ /media/ACR/Documents/PGTS/guidelines/CT _Abdomen_Pelvis.pdf, diakses pada 3 September 2016.

Beeres, M, dkk. 2014. CT Chest and Gantry Rotation Time: does the Rotation Time Influence Image Quality?, The Foundation Ata Radiologia, Sage.

Romans, Lois E. 2011. Computed Tomography Of Technologist, Baltimore, Maryland. 